\title{
ALTERAÇÕES ESTRUTURAIS E FISIOLÓGICAS EM SEMENTES DE COPAIFERA LANGSDORFFII DESF. - LEGUMINOSAE-CAESALPINIOIDEAE SUBMETIDAS AO TRATAMENTO COM HIPOCLORITO DE SÓDIO ${ }^{1}$
}

\author{
LEONARDO GONÇALVES NOLETO²; MARIA DE FÁTIMA RODRIGUES PEREIRA3; \\ LOURDES ISABEL VELHO DO AMARAL ${ }^{4}$
}

\begin{abstract}
RESUMO - O objetivo deste trabalho foi determinar o efeito do hipoclorito de sódio ( $\mathrm{NaClO}$ ) sobre a testa das sementes, germinação e o estabelecimento de plântulas de copaíba. A remoção da cutícula da testa de sementes após imersão em $\mathrm{NaClO}$ a 2,5\% foi evidenciada pelo corante Sudan IV e microscopia eletrônica de varredura. Com a remoção dessa camada ocorreu aumento significativo na absorção de água pela semente, durante a fase inicial da embebição. Substâncias fenólicas, provavelmente inibitórias da germinação, foram detectadas com cloreto férrico nas paredes celulares dos cotilédones. A imersão em $\mathrm{NaClO}$ foi mais favorável para a emergência de plântulas (54\%), quando comparada com a escarificação mecânica (2\%) e controle (14\%). Esses resultados permitem concluir que a utilização do $\mathrm{NaClO}$ é uma alternativa eficaz para a produção de mudas em larga escala, devido principalmente às suas propriedades antissépticas.
\end{abstract}

Termos para indexação: cutícula, embebição, emergência, germinação, plântula.

\author{
STRUCTURAL AND PHYSIOLOGICAL CHANGES IN SEEDS AND SEEDLINGS OF \\ COPAIFERA LANGSDORFFII DESF. (LEGUMINOSAE - CAESALPINIOIDEAE) SUBMITTED \\ TO SODIUM HYPOCHLORITE TREATMENT
}

\begin{abstract}
We determined the effect of Sodium Hypochlorite $(\mathrm{NaClO})$ immersion on the seed coat, germination and establishment of seedlings of Copaifera langsdorffii Desf. (copaiba; diesel tree; kerosene tree; Langsdorf's copaifera). Cuticle removal of the seed coats treated with $2.5 \%$ $\mathrm{NaClO}$ was shown by Sudan IV staining and scanning electronic microscopy. Treatment with $\mathrm{NaClO}$ increased water uptake by the seeds during the early stages of imbibition. The cell walls of cotyledons stained with ferric chloride showed phenolic compounds with putative inhibitory proprieties upon germination. Immersion in $\mathrm{NaClO}$ was the treatment most favorable to seedling emergence (54\%) when compared to mechanical scarification $(2 \%)$ and untreated control seeds $(14 \%)$. These results indicate that $\mathrm{NaClO}$ is an efficient option for large-scale seedling production, principally due to its antiseptic proprieties.
\end{abstract}

Index terms: cuticle, emergence, germination, imbibition, seedling.

${ }^{1}$ Submetido em 11/03/2009. Aceito para publicação em 26/07/2009

${ }^{2}$ Eng. Agr. MSc., Doutorando em Biologia Vegetal, Dpto. Biologia Vegetal, Instituto de Biologia, Universidade Estadual de Campinas (UNICAMP), Cx. Postal 6109, Campinas/SP, CEP 13083-970. E-mail: lnoleto@gmail.com.

${ }^{3}$ Graduação em Ciências Biológicas, Instituto de Ciências Biológicas,
Universidade de Brasília (UnB), Cx. Postal 4457, Brasília/DF, CEP 70919970. E-mail: fatimarodrigues07@gmail.com.

${ }^{4}$ Bióloga, Professora Adjunta, Dpto. Botânica, Instituto de Ciências Biológicas, Universidade de Brasília (UnB), Cx. Postal 04457, Brasília/ DF, CEP 70910-970. E-mail: iamaral@unb.br 


\section{INTRODUÇÃO}

A germinação é um processo fisiológico complexo que se inicia com a entrada de água na semente quiescente e termina com a emergência de parte do eixo embrionário de dentro dos envoltórios seminais (Labouriau, 1983; Bewley, 1997). Em certas circunstâncias, a germinação pode ser impedida ora por condições ambientais inadequadas, ora por mecanismos relacionados à própria semente (Bewley e Black, 1994; Eira e Caldas, 2000). Na família Leguminosae-Caesalpinioideae, a testa é constituída por uma camada externa de células epidérmicas esclerificadas, coberta por uma cutícula; uma camada interna de osteoesclereídeos (hipoderme) e camadas de células parenquimáticas com paredes bastante espessadas (Gunn, 1981; Crestana e Beltrati, 1988). A existência deste conjunto estrutural em muitas das espécies de leguminosas impede a difusão de água e gases em direção ao interior do tecido embrionário (Rolston, 1978; Souza e Marcos-Filho, 2001), caracterizando assim o mecanismo de dormência tegumentar. Embora a dormência seja vantajosa para a sobrevivência das espécies em condições naturais, não é uma característica desejável para a produção de mudas em viveiro. Para fins comerciais é interessante que as sementes germinem sincronizadamente, em curto espaço de tempo, produzindo mudas uniformes (Melo et al., 1998).

A leguminosa Copaifera langsdorffii Desf. possui utilizações madeireira, ornamental e medicinal (Lorenzi, 1992; Veiga Jr. e Pinto, 2002). Essa espécie ocorre no Bioma Cerrado, nas fitofisionomias do Cerrado strictu sensu, cerradão e matas de galeria (Almeida et al., 1998). Contudo, a destruição acelerada dos ecossistemas do Bioma Cerrado nos últimos anos, bem como o extrativismo predatório do óleo medicinal, coloca em risco as populações dessa espécie (Vieira e Silva, 2002).

O comportamento germinativo de C. langsdorffii tem sido descrito na literatura científica e técnica de duas maneiras. Alguns trabalhos recomendam a necessidade de tratamentos de quebra de dormência (Borges et al., 1982; Bezerra et al., 2002), enquanto outros autores asseguram que não há necessidade de tais tratamentos (Lorenzi, 1992). Entre os tratamentos de escarificação já testados para a espécie figuram a escarificação mecânica com lixas (Machado et al., 1992); imersão em ácido sulfúrico (Bezerra et al., 2002) e em água parada por 72 horas (Borges et al., 1982). Esse último tratamento foi eficiente, provavelmente devido à lixiviação de substâncias fenólicas inibidoras presentes nas sementes (Moris e Monteiro, 1959; Pólo e Paes, 1994). Todavia, todos esses trabalhos carecem de informações mais detalhadas sobre o processo germinativo ao longo do tempo.

Estudos sobre a emergência de plântulas abordam aspectos ligados à maturidade das sementes de C. langsdorffii (Polo e Paes, 1994; Pereira et al., 2007) e a utilização de hipoclorito de sódio $(\mathrm{NaClO})$ para assepsia das sementes dessa espécie (Souza-Silva et al., 2001). Entretanto, os efeitos de tratamentos de escarificação sobre aspectos relacionados à estrutura da semente e a emergência de plântulas ainda precisam ser elucidados.

Desta forma, o objetivo deste trabalho foi avaliar o efeito do tratamento de sementes com hipoclorito de sódio $(\mathrm{NaClO})$, sobre a estrutura da testa de sementes, a germinação e a emergência de plântulas de $C$. langsdorffii, por meio de testes histoquímicos e fisiológicos.

\section{MATERIAL E MÉTODOS}

Sementes de Copaifera langsdorffii Desf. foram coletadas em agosto de 2005, de 16 árvores matrizes localizadas em Brasília-DF. Para os experimentos de germinação e emergência, as sementes foram imersas durante 60 minutos em $\mathrm{NaClO}$ com 2,5\% de cloro ativo (Noleto e Silveira, 2004). Para fins comparativos, amostras de sementes foram mantidas intactas (tratamento controle) ou foram escarificadas mecanicamente com bisturi, na sua região mediana. Em cada tratamento, foram realizadas quatro repetições de 25 sementes.

O processo de embebição foi aferido a cada seis horas, durante 78 horas, através do incremento médio de massa fresca das sementes imersas em água destilada.

As sementes foram colocadas para germinar em placas de petri de $9 \mathrm{~cm}$ de diâmetro, em condições controladas em câmara de crescimento com lâmpadas fluorescentes (luz do dia) de $40 \mathrm{~W}$ com irradiância de $30 \mu$ moles. $\mathrm{m}^{-2} \cdot \mathrm{s}^{-1}$, fotoperíodo de 16 horas e temperatura de $24 \pm 2{ }^{\circ} \mathrm{C}$. Foram aferidos a porcentagem e os tempos médios de germinação durante 25 dias (Labouriau, 1983; Santana e Ranal, 2004). Considerouse germinada a semente com emissão da radícula (Labouriau, 1983).

Para os experimentos de emergência em viveiro foram utilizados copos de plástico de $200 \mathrm{~mL}$, descartáveis, perfurados e preenchidos com uma mistura de substrato agrícola comercial(Plantmax $\left.{ }^{\circledR}\right)$, solo do Cerrado e vermiculita, em proporções iguais. As sementes foram semeadas a 2,5 cm de profundidade e mantidas em viveiro sombreado por dosséis de árvores, com área de aproximadamente $2 \mathrm{~m}^{2}$, por 100 dias. Foram consideradas emergidas as plântulas que possuíam aproximadamente: hipocótilo com $5 \mathrm{~cm}$ de comprimento, epicótilo com $9 \mathrm{~cm}$ de comprimento e eófilos com $20 \mathrm{~cm}^{2}$. Foi 
determinada a porcentagem, os tempos médios e a frequência relativa de emergência de plântulas (Labouriau, 1983; Santana e Ranal, 2004). Os dados finais de germinação e emergência foram submetidos à análise de variância, no delineamento inteiramente ao acaso com três tratamentos e quatro repetições. Utilizou-se o teste de Tukey ao nível 5\% de significância para a comparação de médias.

Fragmentos de sementes maduras não embebidas, do tratamento de imersão em $\mathrm{NaClO}$ e do tratamento controle, foram extraídos com bisturi e seccionados transversalmente em micrótomo de mesa, com aproximadamente $10 \mu \mathrm{m}$ de espessura. Para a detecção de lipídios, os cortes foram corados com Sudan IV a 2\% (Johansen, 1940). Para a detecção de compostos fenólicos, os cortes foram imersos em solução contendo cloreto férrico a 10\%, durante 10 minutos (Johansen, 1940).

Para a microscopia eletrônica de varredura (MEV), amostras de fragmentos da testa foram fixados em glutaraldeído a $2 \%$ e paraformaldeído a $2 \%$ em tampão cacodilato, $0,05 \mathrm{M}$, pH 7,2; desidratadas em série crescente de acetona; submetidas ao método do ponto crítico (Robards, 1978); recobertas com carbono e ouro (10-15A de espessura) e analisadas ao microscópio eletrônico de varredura (JEOL JSM 840A) a $20 \mathrm{kV}$.

\section{RESULTADOS E DISCUSSÃO}

A absorção de água pelas sementes foi acompanhada durante 78 horas, período que compreende o início da embebição (sementes secas) e a estabilização da curva (Figura 1). As sementes do tratamento controle de Copaifera langsdorffii apresentaram lenta taxa de embebição, quando comparadas com os tratamentos de escarificação mecânica e imersão em $\mathrm{NaClO}$. No período entre 72 e 78 horas da curva de embebição há tendência de aumento da absorção de água nas sementes controle (Figura 1). Esses resultados evidenciam uma resistência ao fluxo de água para o interior das sementes do tratamento controle, decorrente da restrição mecânica imposta pela testa, no estádio inicial de embebição.

A absorção de água pelas sementes submetidas aos tratamentos de escarificação mecânica e imersão em $\mathrm{NaClO}$ é mais rápida do que no tratamento controle (Figura 1), devido a danos localizados na testa (punção) ou à remoção parcial da cutícula pelo $\mathrm{NaClO}$ (Figura 2B e 2D), quando comparada com a absorção no tratamento controle (Figura 2A e 2C). Embora o tempo necessário para a embebição das sementes no tratamento controle seja bem maior que nos tratamentos de escarificação mecânica e imersão em hipoclorito, não é determinante para a germinação. As sementes de todos os tratamentos apresentaram comportamento germinativo semelhante em placas de petri (Figura 3).

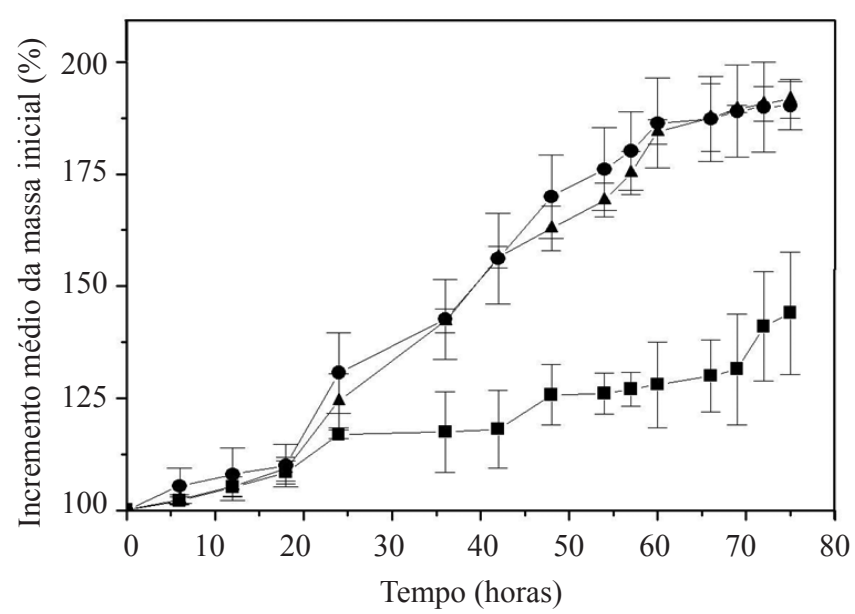

FIGURA 1. Absorção de água por sementes tratadas e intactas de Copaifera langsdorffii Desf., durante 78 horas. ( $\square$ - Controle, Escarificação mecânica, $\Delta$ - Imersão em $\mathrm{NaClO}$ a $2,5 \%$ por 60 minutos. Barras verticais representam intervalos de confiança a $5 \%$ de significância).

O padrão de embebição das sementes submetidas aos tratamentos de escarificação mecânica e imersão em $\mathrm{NaClO}$ diferiu do padrão trifásico clássico na primeira fase (Figura 1). O padrão clássico de embebição é dividido em três fases (Bewley e Black, 1994; Bewley, 1997; Castro et al., 2004): uma fase de rápida embebição (Fase I), seguida de uma fase de estabilização (definida por um platô - Fase II) e uma fase de crescimento e desenvolvimento do embrião (Fase III). Nas sementes de C. langsdorffii, a primeira fase é caracterizada pela lenta absorção de água entre 0 e 18 horas (Fase I A), tornando-se mais rápida entre 18 a 60 horas (Fase I B). A estabilização da curva ocorre entre 60 a 78 horas (Fase II). Além disso, o tempo necessário para a completa embebição das sementes é muito maior do que encontrado na maioria das espécies, tais como Bixa orellana (Amaral et al., 1995); Caesalpinia pyramidalis (Dantas et al., 2008); Eremanthus erythropappus (Davide et al., 2008) e Lupinus luteus (Garnczarska et al., 2007). O padrão encontrado em C. langsdorffii deve-se, provavelmente, ao alto teor de xiloglucanos (40\%) nos cotilédones (Buckeridge et al., 1992), que exercem papel de matrizes hidrofílicas. 


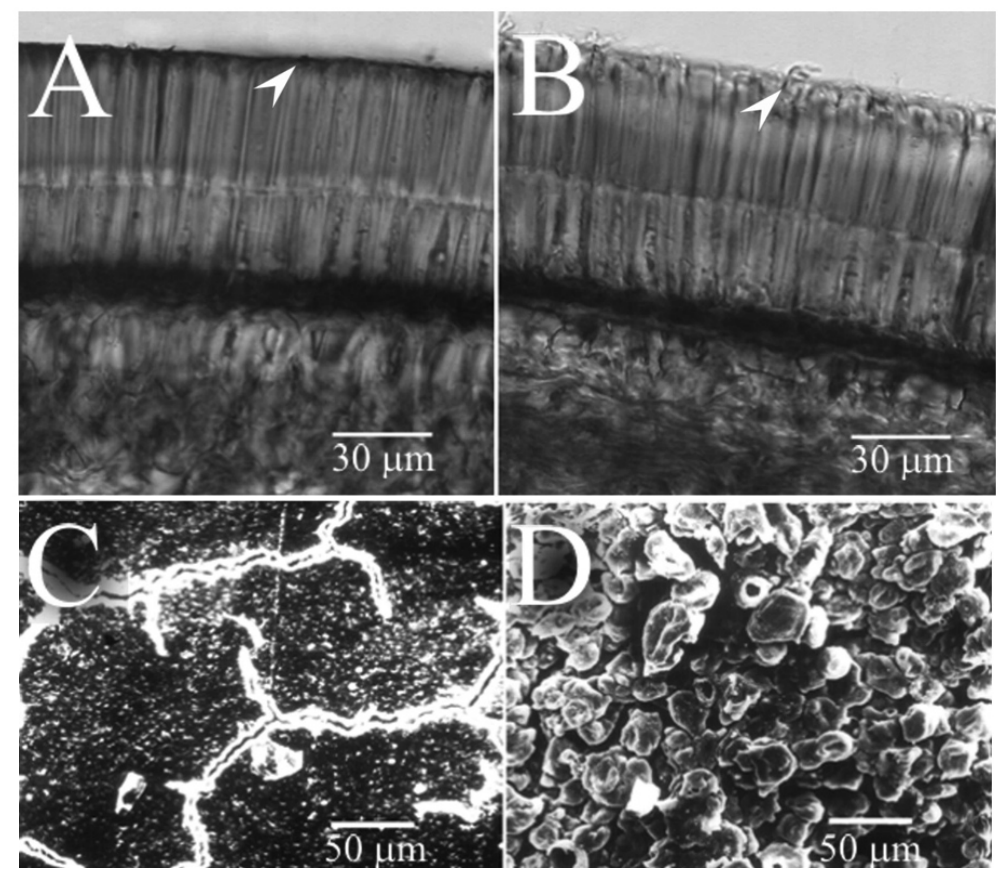

FIGURA 2. Cortes transversais (A, B) corados com Sudan IV e eletromicrografia de varredura (C, D) da superfície da testa da semente de Copaifera langsdorffii Desf. (A - Testa da semente intacta mostrando a cutícula (ponta da seta); B - testa da semente imersa em $\mathrm{NaClO}$ a 2,5\% por 60 minutos, evidenciando a remoção da cutícula e exposição da camada em paliçada (ponta da seta); $\mathrm{C}$ - testa da semente intacta com cutícula preservada; D - testa de semente imersa em $\mathrm{NaClO}$ a $2,5 \%$ por 60 minutos, com exposição dos macroesclereídeos da camada em paliçada após a remoção da cutícula).

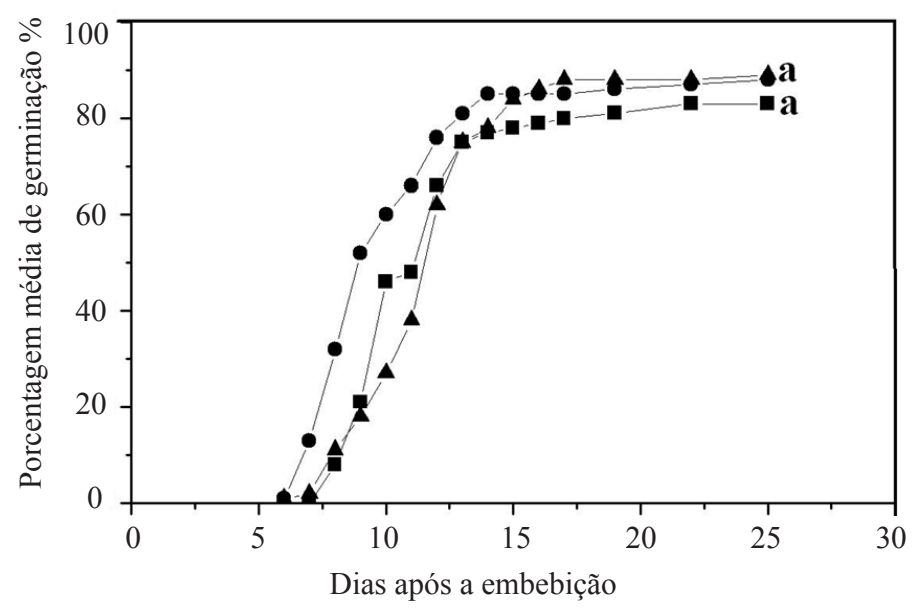

FIGURA 3. Porcentagem acumulada de germinação de sementes de Copaifera langsdorffii Desf. nos tratamentos controle ( $\square$ ), escarificação mecânica $(\bullet)$ e imersão em $\mathrm{NaClO}$ a $2,5 \%$ por 60 minutos $(\Delta)$, em laboratório. Médias com letras iguais não diferem entre si pelo teste de Tukey a $5 \%$ de probabilidade.
As sementes começaram a germinar a partir do $6^{\circ}$ dia de embebição. Aos 25 dias, a porcentagem de germinação das sementes dos tratamentos controle (83\%), escarificação mecânica (89\%) e imersão em $\mathrm{NaClO}(88 \%)$ se estabilizaram, atingindo valores que não diferiram entre si estatisticamente (Figura 3). Os tratamentos de escarificação mecânica e imersão em $\mathrm{NaClO}$ aceleraram o processo de embebição, mas não a germinação, conforme indicam os valores de tempo médio obtidos nos três tratamentos (Tabela 1). Como a rápida embebição apresentada nos tratamentos de escarificação mecânica e imersão em $\mathrm{NaClO}$ não refletem diminuição do tempo médio de germinação, outros eventos poderiam estar envolvidos no processo germinativo da espécie, tais como substâncias inibidoras (Bewley e Black, 1994). Substâncias fenólicas detectadas nas paredes celulares dos cotilédones da semente (Figura 4) poderiam exercer esse papel. Moris e Monteiro (1959) e Polo e Paes (1994) detectaram nesta espécie a presença de cumarinas, que são substâncias fenólicas consideradas inibitórias da germinação (Válio, 1973). Desta forma, infere-se que o período decorrido entre o início da embebição e a germinação seja necessário para a eliminação dessas substâncias, como observado empiricamente por 
Borges et al. (1982), que associou o tempo de permanência das sementes em água parada por até 96 horas e consequente germinação com o odor de cumarina.

TABELA 1. Tempo médio de germinação de sementes de Copaifera langsdorffii Desf. nos tratamentos controle, escarificação mecânica e imersão em $\mathrm{NaClO}$, em laboratório.

\begin{tabular}{cc}
\hline Tratamento & $\begin{array}{c}\text { Tempo médio de } \\
\text { germinação (dias) }\end{array}$ \\
\hline Controle & $11,09 \pm 2,53$ \\
Escarificação mecânica & $9,94 \pm 3,07$ \\
Imersão em NaClO & $11,67 \pm 2,76$ \\
\hline
\end{tabular}

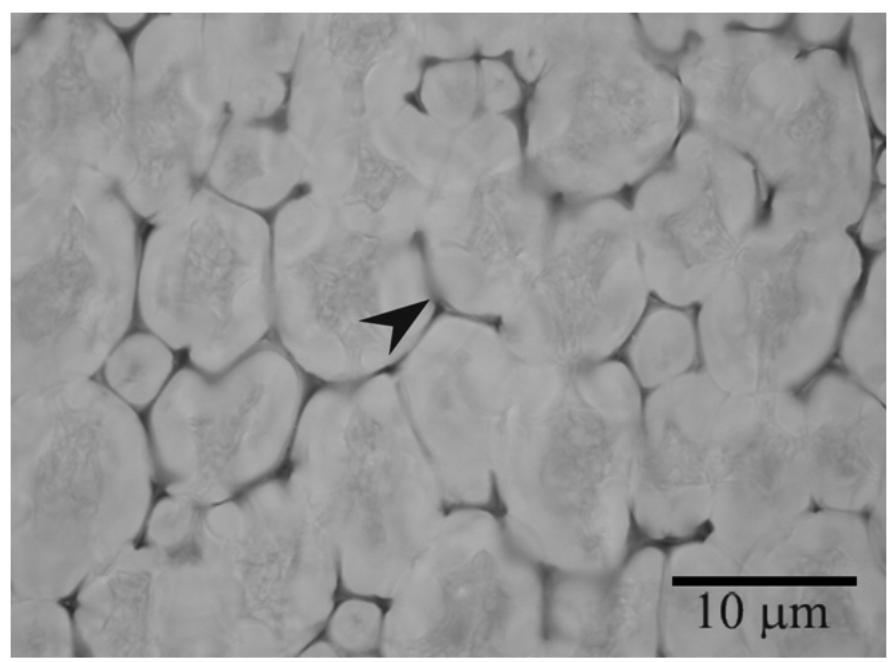

FIGURA 4. Corte transversal dos cotilédones da semente madura de Copaifera langsdorffii Desf., corada com cloreto férrico, evidenciando compostos fenólicos (em preto-ponta da seta) associados à parede celular.

Além da germinação, o estabelecimento de plântulas em condições naturais também é um parâmetro importante a ser considerado. Em C. langsdorffii, a emergência foi significativamente mais alta no tratamento de imersão em $\mathrm{NaClO}$ (54\%), quando comparada com a escarificação mecânica (2\%) e o controle (14\%), nos 100 dias analisados (Figura 5). A frequência relativa de emergência (Figura 6) também indica melhor desempenho do tratamento de imersão em $\mathrm{NaClO}$, embora o tempo médio deste tratamento (Tabela 1) não tenha diferido do controle.

No ensaio em placas de petri, o tratamento de escarificação

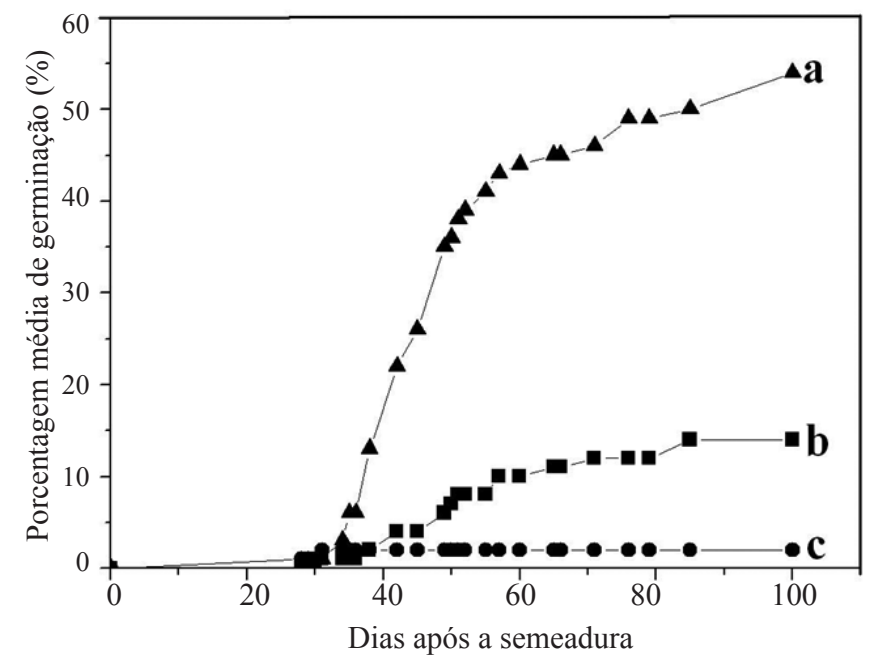

FIGURA. 5. Porcentagem acumulada de plântulas emergidas de Copaifera langsdorffii Desf. nos tratamentos controle ( $\square$ ), escarificação mecânica (๑) e imersão em $\mathrm{NaClO}$ a $2,5 \%$ por 60 minutos $(\Delta)$, em viveiro durante 100 dias. Médias com letras iguais não diferem entre si pelo teste de Tukey a $5 \%$ de probabilidade

mecânica não diferiu dos demais, contudo nos experimentos de emergência em viveiro este tratamento apresentou valor significativamente menor aos outros tratamentos, devido, provavelmente, ao ataque por microrganismos. Conforme Mohamed-Yassen et al. (1994), a testa exerce função protetora da semente contra microrganismos, ficando assim evidente a maior suscetibilidade de sementes escarificadas mecanicamente e mantidas em substrato (no viveiro) do que em condições controladas (em placas de petri).

Em ensaios de germinação de espécies nativas do Cerrado, Souza-Silva et al. (2001) obtiveram dados similares utilizando $4 \%$ de $\mathrm{NaClO}$ por cinco minutos. Esse comportamento deve-se provavelmente ao efeito asséptico exercido pelo $\mathrm{NaClO}$ sobre as sementes de C. langsdorffii, uma vez que não foram observadas diferenças entre os tratamentos nos ensaios de germinação em placas de petri.

Face ao exposto, pode-se considerar que as sementes de C. langsdorffii não apresentam dormência tegumentar, uma vez que a testa retardou, mas não impediu a entrada de água na semente, como constatado nos experimentos de embebição e germinação. Por outro lado, o $\mathrm{NaClO}$ a 2,5\% por 60 minutos causou alterações na estrutura da testa das sementes, acelerando o processo de embebição. 


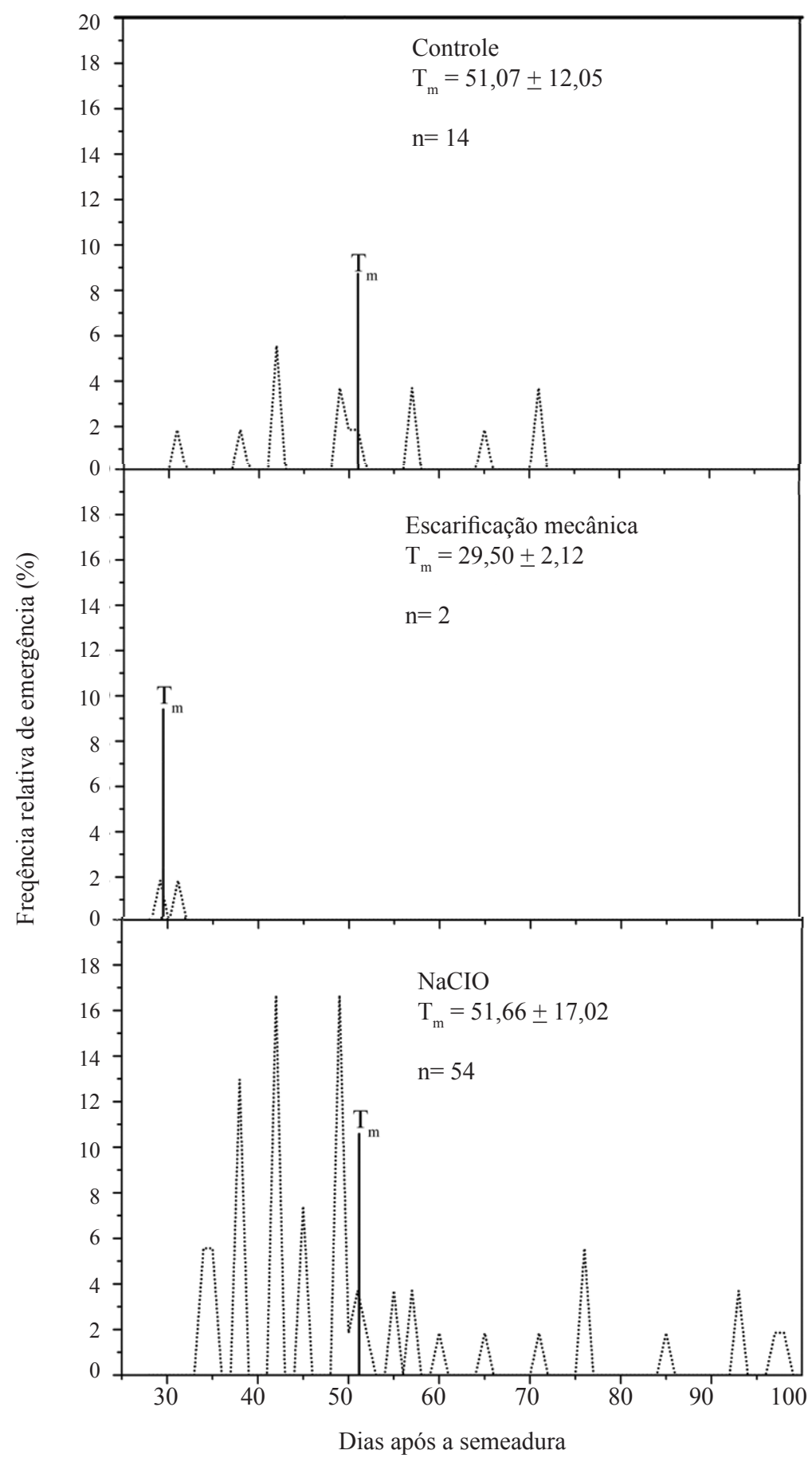

FIGURA 6. Freqüências relativas de emergência de plântulas de Copaifera langsdorffii Desf. nos tratamentos controle, escarificação mecânica e imersão em $\mathrm{NaClO}\left(\mathrm{T}_{\mathrm{m}}=\right.$ tempo médio de emergência, $\mathrm{n}=$ número total de sementes emergidas). 


\section{CONCLUSÃO}

As sementes de Copaifera langsdorffii não apresentam dormência tegumentar. $\mathrm{O} \mathrm{NaClO}$ é uma alternativa eficaz para a produção de mudas em larga escala, pois acelera a absorção de água pela semente além de exercer propriedades antissépticas.

\section{AGRADECIMENTOS}

Aos alunos de graduação da Universidade de Brasília, Bernardo Miglio e Raidan Amorim, pela ajuda na condução dos experimentos.

À Prof ${ }^{\text {a }}$. Dra . Sônia Nair Baó do Departamento de Biologia Celular da Universidade de Brasília, pela concessão de uso do microscópio eletrônico de varredura e pela orientação na sua utilização.

À Prof ${ }^{\text {a }}$. Maria de Fátima D. A. Pereira do Departamento de Biologia Vegetal da Universidade Estadual de Campinas, pelas sugestões na revisão deste trabalho.

Aos Professores do Departamento de Botânica da Universidade de Brasília, Conceição E. dos S. Silveira e Luiz A. R. Pereira, pela ajuda na obtenção das fotos de microscopia ótica.

\section{REFERÊNCIAS}

ALMEIDA, S.P.; PROENÇA, C.E.B.; SANO, S.M.; RIBEIRO, J.F. Cerrado: espécies vegetais úteis. Planaltina: EMBRAPA-CPAC, 1998. 464p.

AMARAL, L.I.; PEREIRA, M.F.; CORTELAZZO, A.L. Quebra de dormência em sementes de Bixa orellana. Revista Brasileira de Fisiologia Vegetal, v.7, n.2, 151-157, 1995.

BEWLEY, J.D.; BLACK, M. Seeds: physiology of development and germination. $2^{\text {nd }}$ ed. New York: Plenum Press, 1994. 445p.

BEWLEY, J.D. Seed Germination and Dormancy. The Plant Cell, v.9, n 7, p.1055-1066, 1997.

BEZERRA, A.M.; FILHO, S.M.; MOREIRA, M.G.; MOREIRA, F.J.C.; ALVES, T.T.L. Germinação e desenvolvimento de plântulas de copaíba em função do tamanho e da imersão da semente em ácido sulfúrico. Revista Ciência Agronômica, v.33, n.2, p.79-84, 2002.

BORGES, E.E.L.; BORGES, R.C.G.; CANDIDO, J.F.; GOMES, J.M. Comparação de métodos de quebra de dormência em sementes de copaíba. Revista Brasileira de
Sementes, v.4 n.1 p.9-12, 1982.

BUCKERIDGE, M.S.; ROCHA, D.C.; REID, J.S.G.; DIETRICH, S.M.C. Xyloglucan structure and postgerminative metabolism in seeds of Copaifera langsdorffi from savanna and forest populations. Physiologia Plantarum, v.86, p.145-151, 1992.

CASTRO, R.D.; BRADFORD, K.J.; HILHORST, H.W.M. Embebição e reativação do metabolismo In: FERREIRA, A.G.; BORGHETTI, F. (Ed.) Germinação: do básico ao aplicado. Porto Alegre: Artmed, 2004. p.149-162.

CRESTANA, C.; BELTRATI, C.M. Morfologia e anatomia das sementes de Copaifera langsdorffii Desf. (Leguminosae - Caesalpinioideae). Naturalia, v.13, p.45-54, 1988.

DANTAS, B.F.; CORREIA, J.S.; MARINHO, L.B.; ARAGÃO, C.A. Alterações bioquímicas durante a embebição de sementes de catingueira (Caesalpinia pyramidalis Tul.). Revista Brasileira de Sementes, v.30, n.1, p.221-227, 2008.

DAVIDE, A.C.; SILVA, C.S.J.; SILVA, E.A.A.; PINTO, L.V.A.; FARIA, J.M.R. Estudos morfo-anatômicos, bioquímicos e fisiológicos durante a germinação de sementes de candeia (Eremanthus erythropappus) (DC.) MacLeish. Revista Brasileira de Sementes, v.30, n.2, p.171-176, 2008.

EIRA, M. S.; CALDAS, L. S. Seed dormancy and germination as concurrent processes. Revista Brasileira de Fisiologia Vegetal, v. 12 (Edição Especial) p. 85-104, 2000.

GARNCZARSKA, M.; ZALEWSKI, T.; KEMPKA, M. Water uptake and distribution in germinating lupine seeds studied by magnetic resonance imaging and NMR spectroscopy. Physiologia Plantarum, v.130, p.23-32, 2007.

GUNN, C.R. Seeds of leguminosae. In: POHILL, R.M.; RAVEN, P.H. (Eds.). Advances in Legume Systematics. Richmond: Royal Botanic Gardens, Kew, 1981. p. 913-925.

JOHANSEN, D.A. Plant microtechnique. New York: McGraw-Hill Book Co. Inc., 1940. 523p.

LABOURIAU, L.G. A germinação de sementes. Washington: O.E.A. 1983. 174p.

LORENZI, H. Árvores brasileiras: manual de identificação e cultivo de plantas arbóreas nativas do Brasil. Nova Odessa: Instituto Plantarum, 1992. 352p.

MOHAMED-YASSEN, Y.; BARRINGER, S.A.; SPLITTSTOESSER, E.; CONSTANZA, S. The role of seed coat in seed viability. The Botanical Review, v.60, n.4, p. 426-439, 1994. 
MACHADO, J.W.B.; ALENCAR, F.O.C.C.; RODRIGUES, M.G.P. Árvores de Brasília. Brasília, DF: GDF, 1992.100p.

MELO, J.T.; SILVA, J.A.; TORRES, R.A.A.T.; SILVEIRA, C.E. S.; CALDAS, L.S. Coleta, propagação e desenvolvimento inicial de espécies nativas do Cerrado. In: SANO, S.M.; ALMEIDA, S.P.(Ed.). Cerrado: ambiente e flora. Planaltina: EMBRAPA-CPAC, 1998. p.195-243.

MORIS, W.B.; MONTEIRO, H.J. Duas cumarinas nas sementes de Copaifera langsdorffii Desf. Anais da Associação Brasileira de Química, v.18 n.3, p.181-182, 1959.

NOLETO, L.G.; SILVEIRA, C.E.S. Micropropagação de copaíba: propagação in vitro de Copaifera langsdorffii. Biotecnologia Ciência e Desenvolvimento, v.33, n.2, p.109-120, 2004.

PEREIRA, R.S.; RANAL, M.; DORNELES, M.C.; SANTANA, D. G.; BORGES, K.C.F.; CARVALHO, M.P. Emergência de plântulas de Copaifera langsdorffii Desf. Revista Brasileira de Biociências, v.5 (suplemento), n.2, p. 1005-1007, 2007.

POLO, M.; PAES, J.P.A. Compostos cumarínicos em sementes imaturas de copaíba vermelha (Copaifera langsdorff Desf.). Revista da Universidade de Alfenas, v.1, n.5, p. 26-29, 1994.

ROBARDS, A.W. An introduction to techniques for scanning electron microscopy of plant cells. In: HALL, J.L. (Ed.). Electron microscopy and cytochemistry of plant cells. New York: Elsevier, 1978, p. 343-444.
ROLSTON, M. P. Water impermeable seed dormancy. The Botanical Review, v.44, n.3, p. 365-396, 1978.

SANTANA, D.G.; RANAL, M.A. Análise da germinação - um enfoque estatístico. Brasília, DF: Editora Universidade de Brasília, 2004. 248p.

SOUZA, F.H.D.; MARCOS-FILHO, J. The seed coat as a modulator of seed-environment relationship in Fabaceae. Revista Brasileira de Botânica, v.24, n.4, p.365-375, 2001 .

SOUZA-SILVA, J.C.; RIBEIRO, J.F.; FONSECA, C.E.L.; ANTUNES, N.B. Germinação de sementes e emergência de plântulas de espécies arbóreas e arbustivas que ocorrem em matas de galeria. In: RIBEIRO, J.F.; FONSECA, C.E.L; SOUSA-SILVA, J.C. (Ed.). Cerrado: caracterização e recuperação de matas de galeria. Planaltina: Embrapa Cerrados, 2001. p.379-422.

VALIO, I.F.M. Effect of endogenous coumarin on the germination of seeds of Coumarouna odorata Aublet. Journal of Experimental Botany, v.24, n.2, p.442-449, 1973.

VEIGA JUNIOR, V.F.; PINTO, A.C. O gênero Copaifera L. Química Nova, v. 25, n. 2, p. 273-286, 2002.

VIEIRA, R. F.; SILVA, S.R. (Coord). Estratégias para conservação e manejo de recursos genéticos de plantas medicinais e aromáticas: resultados da $1^{\mathrm{a}}$ reunião técnica. Brasília: Embrapa Recursos Genéticos e Biotecnologia, Instituto Brasileiro do Meio Ambiente e dos Recursos Naturais Renováveis (IBAMA), Conselho Nacional de Desenvolvimento Científico e Tecnológico (CNPq), 2002. p.146-150. 